after administration of sodium bicarbonate in the distressed newborn infant. Acta Neurol. Scand., 57: 239 (1978).

12. Lou, H. C., Lassen, N. A., and Friis-Hansen, B.: Impaired autoregulation of cerebral blood flow in the distressed newborn infant. J. Pediatr., 94: 118 (1979).

13. Lovett Doust, J. W. and Lovett Doust, J. N.: Aspects of the cerebral circulation during non-REM sleep in healthy controls and psychiatric patients, as shown by rheoencephalography. Psychophysiology, 12: 493 (1975).

14. Murray, P. W.: Field calculations in the head of a newborn infant and their application to the interpretation of transcephalic impedance measurements. Med. Biol. Eng. Comput., 19: 538 (1981).

15. Namon, R., Gollan, F., Shimojyo, S., Sano, R. M., Markovich, S. E., and Scheinberg, P.: Basic studies in rheoencephalography. Neurology, 17: 239 (1967).

16. Oleson, J., Paulson, O. B., and Lassen, N. A.: Regional cerebral blood flow in man determined by the initial slope of the clearance of intra-arterially injected ${ }^{133}$ Xe. Stroke, 2: 519 (1971).

17. Pape, K. E., Blackwell, R. J., Cusick, G., Sherwood, A., Houang, M. T. W., Thorburn, R. J., and Reynolds, E. O. R.: Ultrasound detection of brain damage in preterm infants. Lancet, $1: 1261$ (1979).

18. Pape, K. E. and Wigglesworth, J. S.: Haemorrhage, ischaemia and the perinatal brain. Clinics in Developmental Medicine, London: Publ. Heinemann, for Spastics International Medical Publications. (1979).

19. Papile, L-A., Burstein, J., Burstein, R., and Koffler, H.: Incidence and evolution of subependymal and intraventricular haemorrhage: a study of infants with birthweights less than 1500 gm. J. Pediatr., 92: 529 (1978).

20. Peura, R. A., Wheeler, W. H., Renney, B. C., and Arcuri, J.: Impedance plethysmography: relative contribution of blood volume and red cell velocity changes on the signal strength. Digest of the 11 th. International Conference of Medical and Biological Engineering. Ottawa, Canada, 240 (1976).

21. Rahilly, P. M.: Effects of $2 \%$ carbon dioxide, $0.5 \%$ carbon dioxide and $100 \%$ oxygen on cranial blood flow of the human neonate. Pediatrics, 66: 685 (1980).

22. Robinson, R. O., Rolfe, P., and Sutton, P.: Non-invasive method for measuring intracranial pressure in normal newborn infants. Dev. Med. Child. Neurol., 19: 305 (1977).

23. Weindling, A. M., Murdoch, N., and Rolfe, P.: The effect of electrode size on the contributions of intracranial and extracranial blood flow to the cerebral electrical impedance plethysmogram. Med. Biol. Eng. Comput., 20: 545 (1982).

24. Received for publication July 26,1982 .

25. Accepted for publication April 8, 1983.

\title{
Short Communication. Role of Agar Beads in the Pathogenicity of Pseudomonas aeruginosa in the Rat Respiratory Tract
}

\author{
MARCELO C. NACUCCHIO, ${ }^{(10)}$ M. CRISTINA CERQUETTI, ROBERTO P. MEISS, AND \\ DANIEL O. SORDELLI
}

Facultad de Farmacia y Bioquímica, Universidad de Buenos Aires, Argentina

\section{Summary}

Sterile agar beads plus Pseudomonas aeruginosa injected intratracheally produced local infection in rats, similar to that described for the injection of agar beads containing the same pathogen. It is suggested that it is not necessary for $P$. aeruginosa to be inside the beads to induce lung infection.

\section{Abbreviation}

cfu, colony forming unit

In 1979, Cash and coworkers (2) described a rat model for chronic pulmonary Pseudomonas aeruginosa infection that consisted of intratracheal injection of agar beads containing the pathogen. Other investigators have used a similar system to produce models in guinea pigs (1) and cats (8). Different mechanisms have been proposed to explain enhanced Pseudomonas pathogenicity, not only in the Cash rat model, but also in human disorders like cystic fibrosis. There has been some speculation, for example, that coating of Pseudomonas by mucoid substances may provide survival advantages in the respiratory tract by protecting the microorganisms from phagocytic cells, antibodies and even antibiotics $(4,5,6)$. The importance of bacterial adherence to the epithelia, before replication and microcolony formation has also been recognized (7). In this report we present histopathologic and bacteriologic data obtained from rats in- jected intratracheally either with agar beads containing $P$. aeruginosa, agar beads mixed with $P$. aeruginosa or $P$. aeruginosa alone.

\section{MATERIALS AND METHODS}

Young adult outbred Wistar rats, $140-160 \mathrm{~g}$ in weight, were anesthetized with ether, and a small midline cervical incision was made to expose the trachea. Then, $0.20 \mathrm{ml}$ of the inoculum was injected intratracheally. One group was injected with agar beads containing $10^{5}$ cfu of $P$. aeruginosa; a second group received $10^{5} \mathrm{cfu}$ of $P$. aeruginosa; and the last group was injected with sterile agar beads plus $10^{5}$ cfu of $P$. aeruginosa, mixed immediately before injection. $P$. aeruginosa ATCC 15152 was cultured overnight in $15 \mathrm{ml}$ tryptic soy broth at $37^{\circ} \mathrm{C}$; the pelleted cells were washed with cold saline, and resuspended in phosphate buffered saline, $\mathrm{pH}$ 7.2. Agar beads were prepared with or without $P$. aeruginosa as described previously (2). Groups of animals were sacrificed with a single dose of Nembutal (Abbott Laboratories, North Chicago, IL). The lungs were excised and the gross pathologic features recorded. The left lung was fixed by immersion in $10 \%$ buffered formalin and stained with hematoxylineosin. The right lung was homogenized in $5 \mathrm{ml}$ of cold distilled water in a Potter-Elvehjem homogenizer and appropriate dilutions of the homogenates plated for quantitation purposes in tryptic soy agar. Homogenate samples were also cultured in blood agar and eosin-methylene blue agar plates. Infecting flora were identified in each case by standard clinical laboratory procedures. 
Table 1. Rat lung histopathology after intratracheal injection of P. aeruginosa within, mixed with, and without agar beads*

\begin{tabular}{|c|c|c|c|}
\hline \multirow[b]{2}{*}{$\begin{array}{c}\text { Pathology } \\
\text { (degree) }\end{array}$} & \multicolumn{3}{|c|}{ Intratracheal injection of } \\
\hline & $\begin{array}{l}\text { Pseudomonas } \\
\text { in agar } \\
\text { beads } \\
\text { (a) }\end{array}$ & $\begin{array}{l}\text { Pseudomonas } \\
\text { plus agar } \\
\text { beads } \\
\text { (b) }\end{array}$ & $\begin{array}{c}\text { Pseudomonas } \\
\text { alone } \\
\text { (c) }\end{array}$ \\
\hline No signs $(-)$ & 3 & 2 & 4 \\
\hline $\begin{array}{l}\text { Discrete in- } \\
\text { flammation } \\
(+)\end{array}$ & 1 & 1 & 4 \\
\hline $\begin{array}{l}\text { Leukocyte in- } \\
\text { filtration in } \\
\text { peribron- } \\
\text { chial } \\
\text { and bron- } \\
\text { chial re- } \\
\text { gions }(++)\end{array}$ & 1 & 2 & 2 \\
\hline $\begin{array}{l}\text { Leukocyte in- } \\
\text { filtration } \\
\text { with exten- } \\
\text { tion to pa- } \\
\text { renchyma } \\
\text { and alveoli } \\
(+++)\end{array}$ & 5 & 4 & 0 \\
\hline Sample size & $\begin{array}{c}10 \\
\text { c } v s \text { a, b: } P<0.0\end{array}$ & $\begin{array}{c}9 \\
\text { and a } v s \text { b: N.S. } \dagger\end{array}$ & 10 \\
\hline
\end{tabular}

* Animals were sacrificed at 5 -d intervals for $20 \mathrm{~d}$.

$\uparrow$ Significance levels for a $\chi^{2}$ analysis.

\section{RESULTS}

Gross inspection of the lungs revealed foci of necrosis and inflammation, and tan-white nodules of fibrous lesions were occasionally observed. Eleven of 29 rats had lungs with normal macroscopic features; the lungs of two of these 11 had histopathologic changes, one with discrete inflammation and the other with leukocyte infiltration extended to parenchyma and alveoli. All lungs with gross alterations also had histopathologic changes. The results of the microscopic examinations are shown in Table 1. The seven rats without histopathologic changes were found throughout the time of the experiment, and those animals injected with $P$. aeruginos $a$ alone tended to show the highest degree of inflammation only in the 5-d period after injection.

$P$. aeruginosa was isolated from lung homogenates of seven of 10 rats injected with agar beads containing the pathogen. Three negative cultures corresponded to the three rats with normal lungs. Similarly, seven of nine cultures were positive for those rats injected with the mixture of agar beads plus $P$. aeruginosa, and the two negative cultures corresponded again to those rats with normal lungs. $P$. aeruginosa was isolated from animals that had been injected with $P$. aeruginosa alone only in the group sacrificed $24 \mathrm{~h}$ after injection. The lung of only one of all the rats used in the experiment was colonized with a distinctive flora. Proteus mirabilis was isolated from the lungs of an animal injected with $P$. aeruginosa plus agar beads and sacrificed $15 \mathrm{~d}$ after injection. The number of cfu of $P$. aeruginosa isolated from lungs of animals injected with $P$. aeruginosa inside or plus agar beads varied from $2 \times 10^{6}$ to $5 \times 10^{8}$ per right lung, and the results of the counts for both groups overlapped.

\section{DISCUSSION}

The precise role of agar beads in the enhancement of Pseudomonas pathogenicity is still unclear. Agar beads, however, a) can induce pulmonary inflammation which lasts for up to $7 \mathrm{~d}(2), b$ ) may provide an appropriate surface for bacterial adherence and growth (3), and c) may obstruct small airways (2), which in turn may lead to infections. In this study, we found that a single intratracheal injection, either with agar beads containing $P$. aeruginosa or agar beads mixed with $P$. aeruginosa, produced similar patterns. These two groups of animals were different from that injected with $P$. aeruginosa alone. Costerton et al. (3) have presented data showing that Pseudomonas encased in agar beads are protected from host lung defense by the agar matrix until they grow out of the beads, produce their own protective exopolysaccharide matrix, and colonize the alveolar surfaces. In conclusion, we present data supporting the enhancing role of agar beads in $P$. aeruginosa pathogenicity and showing that it is not necessary for Pseudomonas to be inside the agar bead in order to replicate and produce chronic respiratory infection.

\section{REFERENCES AND NOTES}

1. Blackwood, L. L. and Pennington, J. E.: Influence of mucoid coating on clearance of Pseudomonas aeruginosa from lungs. Infect. Immun., 32: 443 (1981).

2. Cash, H. A., Woods, D. E., McCullough, B., Johanson, W. G., and Bass, J. A.: A rat model of chronic respiratory infection with Pseudomonas aeruginosa.
Am. Rev. Respir. Dis., 119: 453 (1979).

3. Costerton, J. W., Chan, R., and Lam, J.: The role of bacterial exopolysaccharide in the persistence and pathogenicity of Pseudomonas in cystic fibrosis lungs. Perspectives in Cystic Fibrosis. Proceedings of the 8th International Congress in Cystic Fibrosis. p. 9a. (1980).

4. Govan, J. R. W. and Fyfe, J. A. M.: Mucoid Pseudomonas aeruginosa and cystic fibrosis: resistance of the mucoid form to carbenicillin, flucloxacillin and tobramycin, and the isolation of mucoid variants in vitro. J. Antimicrob. Chemother., 4: 233 (1978).

5. Høiby, N.: Pseudomonas aeruginosa infection in cystic fibrosis, relationship between mucoid strains of Pseudomonas aeruginosa and the humoral immune response. Acta Pathol. Microbiol. Scand. sect. B, 82: 551 (1974).

6. Lam, J., Chan, K., Lam, L., and Costerton, J. W.: Production of mucoid microcolonies by Pseudomonas aeruginosa within infected lungs in cystic fibrosis. Infect. Immun., 28: 546 (1980).

7. Selinger, D. S. Reer, W. P., and McLaren, L. C.: Model for studying bacterial adherence to epithelial cells infected with viruses. Infect. Immun., 32: 941 (1981).

8. Winnie, G., Klinger, J. D., Cheng, P. W., Sherman, J., and Thomassen, M. J.: A feline model for chronic Pseudomonas pulmonary infection. Cystic Fibrosis Club Abstracts, 23rd Annual Meeting, p. 71. (1982).

9. We thank A. Morris Hooke for her help in the correction of the manuscript.
10. Requests for reprints should be addressed to: Marcelo C. Nacucchio, Ph.D., Catedra de Higiene y Sanidad, Facultad de Farmacia y Bioquimica, Universidad de Buenos Aires, Junin 956, 1113 Buenos Aires, Argentina.

11. Received for publication November $4,1982$.

12. Accepted for publication June 3, 1983 . 